\title{
THE UNIVERSITY AND THE EXTERNAL ENVIRONMENT - TOWARDS A COLLABORATIVE SYSTEM OF RESOURCES EXCHANGE
}

\section{WOJCIECH DOWNAR}

University of Szczecin, Faculty of Management and Economics of Services, POLAND

e-mail: wojciech.downar@wzieu.pl

RECEIVED
ACCEPTED
JEL
CLASSIFICATION

KEYWORDS

ABSTRACT

\author{
18 January 2018 \\ 2 September 2018 \\ $114,123,031$
}

higher education, management, networks, innovations

Over the centuries, the role of universities and its impact on economic, social and cultural environment has changed. University relations with the main stakeholders: industry (business) and government have been changing from static and laissez faire to balanced configuration. The cooperation of these entities forms what we can call collaborative system of resources exchange. The main objective of collaboration with parties involved is to develop innovative solutions and to get the added value to each party. Value co-creation in a collaborative system depends on the ability to select and reconfigure individual elements in the way in which the emergence of new knowledge in a synergistic process takes place. University to meet the requirements of functioning in a collaborative system must adapt both its strategy (business model) and its internal processes. On the strategic level organizational culture based on dynamism of action, ability to take risks, willingness to change, ability to take advantage of opportunities, search for new ideas and innovation is of crucial importance. On operational level of crucial importance are relations between the process of knowledge production (research), the process of knowledge transfer (education), and the process of application of knowledge (innovation).

\section{Introduction}

Over the centuries, the role of universities and its impact on economic, social, cultural and even religious life has changed. In respective epochs, the university's relationship with the environment were determined by the concept of university functioning, its role in society, in particular in relations with the State and the Church. The university has always been associated with the external environment, carried out tasks for the environment 
and met the needs of external stakeholders. In the history of higher education, we can recognize three types (generations) of universities: a medieval university, also known as scholastic, a Humboldt university and a third generation university (Leja, 2013, p. 29; Waltoś, Rozmus, 2012, p. 17).

Historically, the first and then the most important commitment of the university to the external environment is to provide personnel, in particular to the State. In the medieval Bologna model of the university, the emphasis was on legal sciences because educated counselors and scholars were required to hold numerous offices, including judges and positions in the church hierarchy.

The Humboldt University have been focused on research in which education was only a part of the university's model of functioning. Although, at the end of the nineteenth century, relationship between the world of science and industry became more important, especially for departments dealing with the research and new technologies development, there was still a definite distinction between universities and industry.

Cooperation between the university and the external environment has become an important element of the concept of the university's functioning in modern times. In addition to two traditional areas of activity, i.e. education and scientific and research activities, one more area was noted, namely building relationships with the external environment.

\section{Models of relations hetween the university and the external environment}

External relations between universities are determined by two main stakeholders, namely the State and enterprises (industry, business). Three models of mutual relations between these stakeholders are presented by Etzkowitz and Leydesdorff (2000, p. 111). Model proposed by authors presents three perspectives illustrating the mutual relations between these three entities, taking into account the leading role of the university, i.e.:

- static configuration,

- laissez faire configuration, and

- balanced configuration.

Static configuration (also referred as the TripleHelix I) assumes that the State plays the leading role by stimulating the activities of the university and industry. At the same time, the State is the initiator and administrator of resources necessary to carry out innovative undertakings. The second perspective is based on different premises, which assumes a limited role of the State, and the driving force are enterprises whose development stimulates activities undertaken by universities and the State. These two entities in the laissez-faire model only fulfil auxiliary functions to the industry (TripleHelix II) (see Figure 1).

The evolution of the university's relationship with the external environment took place not only in the aspect of who is a partner in cooperation, but also in the sense of tasks carried out for the external environment. In this respect, evolution takes place from internally oriented tasks to the use of research and education process for the needs of external stakeholders. As it is often noted, evolution comes from ivory tower (as a metaphor of internally focused university) toward university delivering market-oriented knowledge services.

It is worth emphasizing that university as a science-based company can no longer be an Island unto itself. In a highly competitive global environment, it is necessary to use outside sources of knowledge and technology. Companies increasingly look to universities, as well as to other firms and government laboratories. Cooperative initiatives are emanating from both the academic and industrial spheres, often encouraged by government - at both regional and national levels - and by multinational organisations (Etzkowitz, Leydesdorff, 1998, p. 203). 

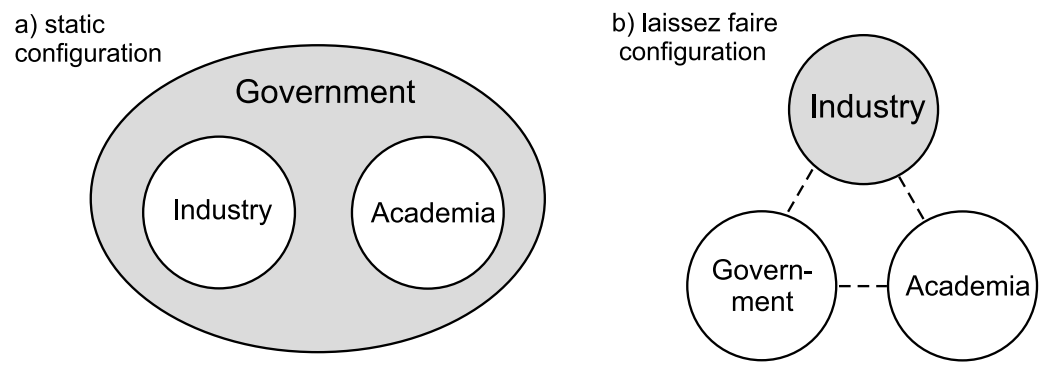

Figure 1. Static and laissez faire configurations between Academia, Industry and Government

Source: based on Etzkowitz, Leydesdorff (2000), p. 111.

The appearance of the third mission of higher education institutions was a natural consequence of social and economic development, increasing global competition and seeking new sources of competitive advantage, which were more and more often perceived in acquiring and using information and knowledge that universities had at their disposal.

Building relations between the university and the external environment related firstly to cooperation with enterprises (industry), later expanding to other areas of socio-economic activity. In particular, together with the development of cooperation with the external environment, joint initiatives of the university and industry were also involved in the state and local government institutions.

It can therefore be concluded that the era of cooperation between universities and the external environment has come. One of the main reason encouraging cooperation is that each partner is looking for resources vital for further development. It can also be stated that the necessity of cooperation results from the fact that in the contemporary, complex economic and social world, no one has full control over resources, including knowledge resources that are necessary, in particular for the implementation of research and development projects.

It is therefore essential to search for opportunities and access to resources available to others building an interdependent network of relations. Currently, the information where resources are available and how to reach them is equally important (and maybe more valuable) than being a resource owner. The reason for the high complexity of the functioning of higher education institutions is also the high degree of interdependence between entities. The cooperation of these entities forms what we can call the collaborative system of resources exchange. The main objective of collaboration with parties involved is to develop innovative solutions and to get the added value to each party as a result.

\section{Triple Helix III as the collaborative system of resources exchange}

The collaborative system of resources exchange can be considered from the point of view of value cocreation. Broadly speaking, co-creation refers to the processes by which two or more parties collaborate, or participate, in creating value for themselves or others. The assumption behind co-creation is that there will be a benefit through the involvement of the relevant parties in developing a product/service/initiative (Hughes, 2014, p. 338). Referring to marketing concepts it can be concluded that firms are working closely with customers and suppliers and are obtaining new insights and knowledge from these sources. If we assume that individual entity 
forming the collaborative system are internal customers to each other, the term collaborative innovation is relevant (Geer, Lei, 2012, p. 65). Moreover subject of exchange in such system are to a greater extent not tangible but intangible assets (knowledge, ideas, relations, methods). The theoretical understanding of value co-creation has been enhanced by the concept of Service Dominant Logic (SDL). SDL argue that increasingly markets have shifted away from the exchange of tangible goods towards the exchange of intangibles, specialized skills and knowledge and processes (Vargo, Lusch, 2008, p. 5). The SDL concept emphasizes the importance of the university in the collaborative system because it assumes that fundamental unit of exchange and the source of economic growth is the application of specialized skills and knowledge (Vargo, Lusch, 2004, p. 5), assets that are at the university's disposal.

Value co-creation in the collaborative systems depends on the ability to select and reconfigure individual elements in the most efficient way. Etzkowitz (2008, p. 76) believes that the configuration of resources determines innovation and thus innovation is defined as the reconfiguration of elements into a more productive combination. Therefore, new knowledge can be created between participants of strategic configurations as a synergy of competences brought in by each party. Such synergistic knowledge is difficult to define because it reflects a complex, dynamic process of exchanging explicit and implicit knowledge, both formal and informal, between organisations participating in the network. The cooperation of these entities implies the existence of an interaction process in which all participants use their resources and competences mutually: the effect of this is the emergence of new knowledge in a synergistic process. Nielsen (2000, p. 7) distinguished complementary and synergistic network of knowledge. Traditional approach assumes knowledge compatibility and complementarity. The focus tends to be on transfer of existing, explicit knowledge rather than creation of new one. Hence, shifting the focus from inter-organisational transfer of complementary knowledge to development and distribution of synergies of knowledge within collaborative system within which new knowledge can be created among the participants in a strategic aggregate arrangement as a synergy.

The third model of mutual relations between enterprises (industry, business), government and academia Etzkowitz, Leydesdorff (2000, p. 112) assumes a balanced configuration, however, due to the fact that universities have the most important resource - knowledge, their role in this configuration is leading (TripleHelix III model).

The objective of this configuration is to create a favourable environment for innovation, to cumulate the development of innovation and to take advantage of the synergy effect possible to achieve as part of joint initiatives of these three entities (see Figure 2). On the one hand, the university provides knowledge, on the other it benefits from the opportunities created by the government (local and regional as well), and other institutions with research needs (joint research projects). The demand for educated employees, as well as regulations that are set by the government (legal, organizational and financial) are also part of resources exchange. Benefits resulting from cooperation with business are manifested both in the area of research projects (demand for research) and projects of an educational nature. An unquestionable advantage for the university that emerges from cooperation with business is the access to new practical solutions that are invaluable help in the modern educational process. 


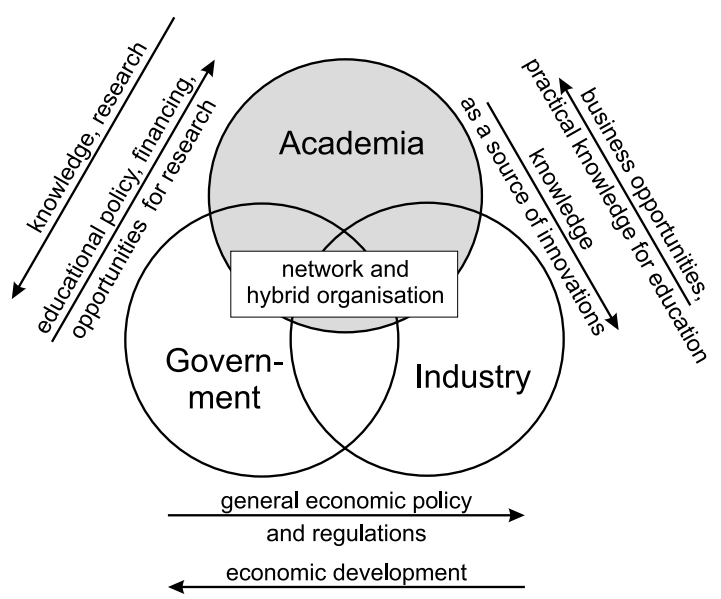

Figure 2. Collaborative system of resources exchange in Triple Helix III model

Source: own elaboration, based on Etzkowitz, Leydesdorff (2000), p. 112.

The Triple Helix III model, in which individual entities strive to create an innovative environment for the creation of spin-off companies, as well as any joint initiatives that take on various forms of network structures, including clusters or hybrid organisations.

The university to meet the requirements of functioning in the collaborative system must adapt both its strategy (business model) and its internal processes. On the strategic level the third generation university must be closely associated with enterprises and entrepreneurs and local authorities, being an integral part of social and economic life. Another name for the university of the third mission or a third generation is the entrepreneurial university. The use of an adjective "entrepreneurial" means that it is characterized by such features as: dynamism of action, focus on market needs, the ability to take risks, the ability to take advantage of opportunities, search for new ideas and innovation. The entrepreneurial university itself tries to act in an innovative way, but also contributes to the innovative application of knowledge and research that it produces. A modern university has to compete for the best lecturers, students as well as contracts and research projects. Such high competitiveness forces the activity of the employees themselves and the people managing the university. It also requires to develop an organizational culture based on entrepreneurship, willingness to change and take risks. As noted by Clark (1998, p. 128), who is considered the creator of the concept, the entrepreneurial university is taking risks when initiating new practices whose outcome is in doubt, actively seeks to innovate, develops a work culture that embraces change. The ability to search for partners, create synergic coalitions, and finally the ability to act in an international environment are also crucial.

On the operational level, the triangle of knowledge can determine the main processes necessary to implement the strategic assumptions of the third mission university. The knowledge triangle shows the relationship between research (the process of knowledge production), education (the process of knowledge transfer) and innovation (the process of application of knowledge) (see Figure 3). 


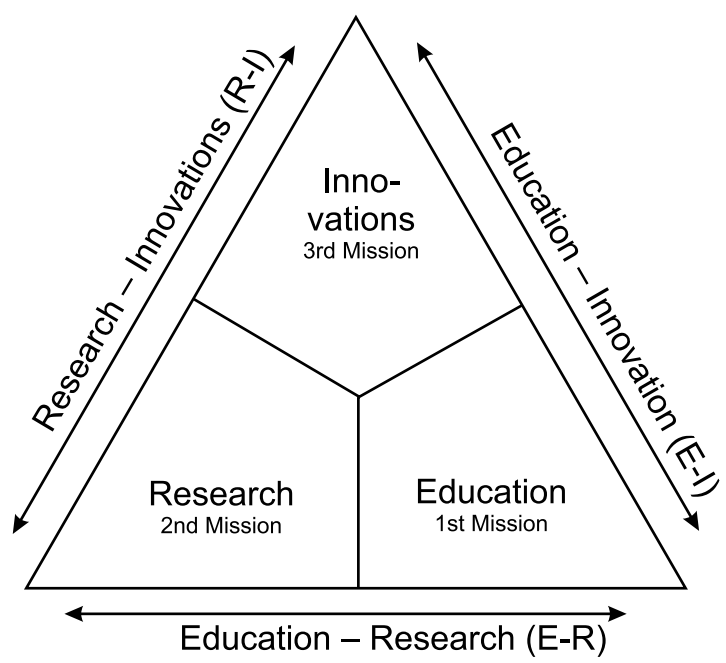

Figure 3. The Knowledge Triangle

Source: own elaboration based on: Grichting (1995), p. 66; Lassnigg, Hartl, Unger, Schwarzenbacher (2017), p. 7.

The implementation of these main processes relies on balancing three areas of the university activity, considering the area of application as the most important. The balancing of these areas can only take place when the mutual relations between them (E-R, E-I and R-I) take the form of synergic cooperation based on the benefits for all participants.

\section{Conclusions}

The relationship between the university and the external environment has undergone a significant evolution over the years. In the system of three partners (university, government, business), the university has a leading role, because it has a wealth of knowledge, which is a huge opportunity, taking into account that initiatives are emanating not only from academic but also industrial spheres, often encouraged by government. Mutual relations between these entities may take different forms, but the target model is the collaborative system of resources exchange in which the subject of the exchange are mainly intangible resources, primarily knowledge and specialized skills. The concept of value co-creation (value emerges in the process of cooperation with partners) in the Triple Helix III model rather than value creation (transfer between partners) is the assumption of the functioning of the cooperation network. The university itself, in order to take advantage of the opportunity that stands before it, should build a balanced system of internal processes implementation (conducting research and educational process), which in turn will form the third process of their application into collaborative innovation.

\section{References}

Clark, B.R. (1998). Creating Entrepreneurial Universities. Organizational Pathways of Transformation. Oxford: Pergamon Press.

Etzkowitz, H., Leydesdorff, L. (1998). The Endless Transition: A 'Triple Helix' of University - Industry - Government Relations. Minerva, 36, 203-208. 
Etzkowitz, H., Leydesdorff, L. (2000). The dynamics of innovation: from National Systems and 'Mode 2' to a Triple Helix of universityindustry-government relations. Research Policy, 29, 109-123.

Etzkowitz, H. (2008). The Triple Helix: University - Industry - Government Innovation in Action. Abingdon: Routledge.

Greer, C., Lei, D. (2012). Collaborative innovation with customers: a review of the literature and suggestions for future research. International Journal of Management Reviews, 14 (1), 63-84.

Grichting, W.L. (1995). The Knowledge Triangle and Australian Universities. Education and Society, 13 (2), 63-75.

Hughes, T. (2014). Co-creation: moving towards a framework for creating innovation in the Triple Helix. Prometheus, 32 (4), $337-350$.

Lassnigg, L., Hartl, J., Unger, M., Schwarzenbacher, I. (2017). Higher Education Institutions and Knowledge Triangle: Improving the interaction between education, research and innovation. Wien: Institut für Höhere Studien (IHS), Abt. Soziologie, 118.

Leja, K. (2013). Zarządzanie uczelnią. Koncepcje i współczesne wyzwania. Warszawa: Oficyna a Wolters Kluwer business.

Nielsen, B.B. (2000). Synergies in Strategic Alliances: Motivation and Outcomes of Complementary and Synergistic Knowledge Networks. Working Papers from Copenhagen Business School, 4, 7.

Vargo, S.L., Lusch, F.R. (2004). Evolving to a New Dominant Logic for Marketing. Journal of Marketing, 68, 1-17.

Vargo, S., Lusch, R. (2008). Service-dominant logic: continuing the evolution. Journal of the Academy of Marketing Science, 36, 1-10.

Waltoś, S., Rozmus, A. (ed.) (2012). Szkolnictwo wyższe w Polsce. Ustrój, Prawo, Organizacja. Kraków, Rzeszów, Zamość: Konsorcjum Akademickie.

Cite this anticle aS: Downar, W. (2018). The university and the external environment - towards a collaborative system of resources exchange. European Journal of Service Management, 3 (27/2), 135-141. DOI: 10.18276/ejsm.2018.27/2-16. 